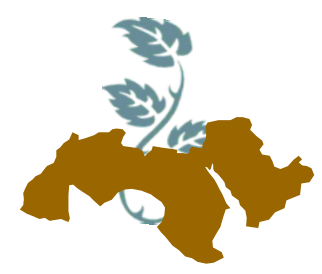

\title{
THE IMPACT OF THE PROBIOTIC BACTERIA ON THE CONTAMINATED MICROBIAL OF THE FEMALE GENITAL TRACT AND ITS EFFECT ON THE IVF OUTCOME
}

\author{
Hagar E. Ali ${ }^{1}$; K.A. El-Dougdoug ${ }^{2}$; M.Y.Soliman ${ }^{3}$; M.M. Hazaa ${ }^{1}$ \\ and M.M. Sowelam ${ }^{1}$ \\ 1- Botany Dept., Fac. of Sci., Benha Univ., Benha, Egypt \\ 2- Agric. Microbiology Dept., Fac. of Agric., Ain Shams Univ., Cairo, Egypt \\ 3- OBS/GYN Dept., Fac. of Medicine, Ain Shams Univ., Cairo, Egypt
}

Keywords: Probiotic bacteria, female genital tract, ivf outcome, Klebsilla sp., E. coli, Candida sp., Lactobacillus sp.

\section{ABSTRACT}

The microbial contamination of the female genital tract has effect on the ivf outcome and negatively effect on fertility, fertilization and implantation rate. Lactobacillus sp. is the dominant organism of the vaginal flora that have an important role in the inhibition of pathogen. 48 patients were selected for this study aged between $20-40$ years, During embryo transfer, 3 samples were collected from each patient from vagina, end cervical canal and the tip of the catheter. The samples were assayed microbiology. The microbial culture contained natural flora and pathogen organism. The isolated pathogens were identified as Klebsilla pneumonia, Escherichia coli, Candida albicans, C. tropicalis, $C$. famata, C. parapsilosis, C. catenulate according to Bergey's manual and confirmed by VITEK System. Candida $s p$ found to be the most frequent in female genital tract. The probiotic (Lactobacillus. acidophilus) and its metabolites (bacteriocin) were inhibited growth of isolated pathogenic microbial in vitro. The result showed that $L$. acidophilus and their metabolite bacteriocin have antagonistic activity against pathogenic microbes.

Recommendation: Oral or transvaginal administration of Lactobacillus or bacteriocin antiseptics; disinfected; maintain a health vagina and prevent the infection of the reproductive tract.

\section{INTRODUCTION}

The bacterial contamination has negatively effect on fertility, fertilization and implantation rate
(Selman, et al 2007). During embryo transfer techniques, embryos are loaded into a transfer catheter that passes through vagina and cervix into the uterus that may lead to possible microbial contamination of the uterine cavity that may alter the susceptibility of the endometerium and embryo implantation (Aboul fotouh, et al 2008). There are many factors that affect on implantation rates such as patient's age, endometrial receptivity and embryo quality (Egbase PE; et al 1999). The presence of pathogenic bacteria such as E.coli and streptococcus viridians decreased live birh rate (Eckert, et al 2003). Disequilibrium in microbiota promote the growth of opportunist microorganisms and the development of pathologies. Vulvovaginal candidiasis (VVC) is overgrowth of candida spp due to the disruption of the vaginal microbiota may be due to pregnancy, antibiotic therapy, use of contraceptives and spermicide, frequent sexual intercourse, diabetes and immunosuppression (Rathod, et al 2014 and Sobel, 2007). Candida albicans is the major causal of yeast Vaginitis but there are another species Candida glabrata, Candida krusei and Candida tropicalis infect the host.

The development of VVC has been associated with the lack of $\mathrm{H}_{2} \mathrm{O}_{2}$-producing lactobacillus species (vitali, et al 2007 and Chakoosari, 2013).

The normal vaginal flora of the human play an important role in preventing colonization of the pathogen including those responsible for bacterial vaginosis, yeast infections, sexually transmitted disease and urinary tract infection (Zhou, et al 2004, Burton, et al 2003). The lactobacillus especially $L$. acidophilus, $L$. cripatus, $L$. jensenii and $L$. iners is the dominant organism of the vaginal flora that have an important role in the inhibition of pathogen (Cannon, 2005 and Hoore, et al 2000). 
Lactobacillus can inhibit the growth of pathogens by two mechanisms: (a) by production of antimicrobial factors that have adverse effect of pathogens such as lactic acid, hydrogen peroxide, bacteriocin and bacteriocin like substance such as nisin, lactobrevin, acidophilin, acidolin, lactobacillin, lactocidin and lactolin (Chakoosari,2013 and Pendharkar et al 2015). (b) by adherence and competition. The mechanism of defence of lactobacillus against candida colonization is the ability of lactobacilli to adhere and compete for receptors sites on vaginal epithelial cells ( Simonetti, et al 2007). This study amis to application Lactobacillus or bacteriocin antiseptics; disinfected to maintain a health vagina and prevent the infection of the reproductive tract.

\section{MATERIALS AND METHODS}

The study took place from April 2015 to December 2016. 48 patients were selected for this study who attending Queens Hospital, suffering from $1^{\text {st }}$ infertility, Cairo, Egypt and undergoing ivf treatment patient's age range between 20-40 years. patients undergoing long protocol treatment. Patients were selected with at least two good quality embryos available for embryo transfer. Three specimens were taken by nutrient broth swaps from each of tip of catheter, vagina and endocervical canal at the time of embryo transfer for each patient and send to the central laboratory, Kasr El-Ainin, Cairo University.

The swabs were cultured on blood agar for isolation, purification of contaminated microbes, The culture colonies were inoculated on macConkey agar for gram negative bacteria, chocolate for anaerobic bacteria and sabouraud dextrose agar for yeast (oxoid. Cairo, Egypt). The isolated bacterial and Candida were identified accordance with Bergey's manual of determinative bacteriology (Holt, et al 1994). The identification of isolates were confirmed by VITEK 2 system using the colorimetric reagent cards that can measure various metabolic activities such as acidification, alkalinization, enzyme hydrolysis and growth in the presence of inhibitory substance. After identification of each isolate, The VITEK2 system was used to detect the antibiotic sensitivity test and determine the minimum inhibitory concenteration.

Antibacterial activity of Lactobacillus acidophilus CL1285: L. acidophilus CL1285 used in this study was obtained from Egypt Microbiology
Culture Collection, Cairo MIRCEN, Fac. of Agric., Ain Shams Univ., Cairo, Egypt. The inhibitory spectrum of Lb. acidophilus CL1285 cells ( $(2 \mathrm{x}$ $10^{6}$ ) and cells free supernatants (CFS) were studied against isolated pathogen in this study (Klebsilla pneumonia, Escherichia coli, Candida albicans, C. tropicalis, C. famata, C. parapsilosis and C. catenulate) in vitro. Lactobacillus inoculated to MRS agar media and incubated for $24 \mathrm{hrs}$ at $30^{\circ} \mathrm{C}$ then divided as disc, the antagonist activity of Lactobacillus acidophilus was studied against pathogenic isolates using agar well diffusion. The CFS was obtained by centrifuging MRS broth cultures incubated for $24 \mathrm{hrs}$ at $30^{\circ} \mathrm{C}$ at $(6,000 \mathrm{rpm}$ for 10 minutes at $\left.4^{\circ} \mathrm{C}\right)$. The CFS was filtered through syringe filter $(0.45 \mu \mathrm{m}$, Millipore). The inhibitory activity of CFS was tested using agar well diffusion method.(Cheesbrough, 2000).

Purification of bacteriocin: The partially purified bacteriocin was described by (Ouda, et al 2014 and Enan, et al 2013). One arbitrary unit (AU $\mathrm{mL}-1$ ) of crude bacteriocin preparation was defined as $5 \mu \mathrm{L}$ of the highest dilution of PPE yielding a definite zone of inhibition of growth in the lawn of indicator organism. The highest dilution was multiplied by $200 \mu \mathrm{L}(1 \mathrm{~mL} / 5 \mu \mathrm{L})$ to obtain the arbitrary units per milliliter (AU mL-1). CFS from $L b$. acidophilus was adjusted at $\mathrm{pH} 6.5$ and was treated with solid ammonium sulfate till $50 \%$ saturation level. The mixtures were stirred for $12 \mathrm{~h}$ at $4^{\circ} \mathrm{C}$ and centrifuged at $\left(14,000 \mathrm{rpm}\right.$ for $1 \mathrm{hr}$ at $\left.4^{\circ} \mathrm{C}\right)$. The pellets were resuspended in $1 \mathrm{mM}$ potassium phosphate buffer, $\mathrm{pH} 6.5$ and dialyzed against the same buffer for $24 \mathrm{hrs}$ at $4 \mathrm{oC}$ in dialysis tubing. This partially purified bacteriocin was sterilized by filtration through syringe filter (Amicon $0.45 \mu \mathrm{m}$, Millipore).

Amino acid composition: Amino Acids were determined by (Csomos, et al 2002). $200 \mu \mathrm{l}$ of purified bacteriocin was hydrolyzed with $6 \mathrm{~N} \mathrm{HCl}$ in sealed tube, heated in oven at $100 \mathrm{oC}$ for $24 \mathrm{hrs}$, to evaporate $\mathrm{HCl}$. The residue was dissolved in diluting citrate buffer ( $\mathrm{pH}$ 6.5). HPLC was performed with an AAA 400 amino acid analyzer (Ingos Ltd., Czech Republic) equipped with an Ostion LG ANB ion exchange column. Free amino acids were separated by stepwise gradient elution using $\mathrm{Na} / \mathrm{K}$ citric buffer system (Ingos Ltd., Czech Republic). Post-column derivatization with minhydrin reagent and spectrophotometric measurement was used for determination of amino acids and biogenic amines. 

female genital tract and its effect on the ivf outcome

\section{RESULTS}

\section{Identification of bacterial \& candidal isolates}

Pathological bacteria and Candida isolated from vagina, endocervical canal and tip of catheter were identified according to Bergey's Manual of Determinative Bacteriology (Holt, et al 1994) and confirmed by VITEK 2 system as $K$. pneumonia, E.coli, C. albicans, C. tropicalis, C. famata, C. parapsilosis and C. catenulate.
The relation between pregnancy and presence of pathogen in the vagina, endocervix and tip of the embryo transfer catheter. The pregnancy rate is lower in the patients with K. pneumonia (6.25\%) compared to with negative microbial growth $(93.75 \%)$. The pregnancy rate is lower in the patients with E. coli (0\%) compared to those with negative microbial growth (100\%). The pregnancy rate is lower in the patients with Candida albicans (18.75\%) compared to those with negative microbial growth $(81.25 \%)$ in (Table 1).

Table 1. Organism isolated from vaginal, endocervical and tip of embryo transfer catheter swaps and its relation on pregnancy outcome

\begin{tabular}{|c|c|c|c|c|c|c|c|c|}
\hline \multirow{3}{*}{$\begin{array}{l}\text { Microbial } \\
\text { Isolates }\end{array}$} & \multicolumn{4}{|c|}{ Pregnant $(n=16)$} & \multicolumn{4}{|c|}{ Non Pregnant $(n=32)$} \\
\hline & \multicolumn{2}{|c|}{$\begin{array}{l}\text { Microbial } \\
\text { growth }\end{array}$} & \multicolumn{2}{|c|}{$\begin{array}{c}\text { No. microbial } \\
\text { growth }\end{array}$} & \multicolumn{2}{|c|}{$\begin{array}{l}\text { Microbial } \\
\text { growth }\end{array}$} & \multicolumn{2}{|c|}{$\begin{array}{c}\text { No. microbial } \\
\text { growth }\end{array}$} \\
\hline & No. & $\%$ & No. & $\%$ & No. & $\%$ & No. & $\%$ \\
\hline K. pneumonia & $1 / 16$ & 6.25 & $15 / 16$ & 93.75 & $3 / 32$ & 9.37 & $29 / 32$ & 90.62 \\
\hline E. coli & $0 / 16$ & 0 & $16 / 16$ & 100 & $2 / 32$ & 6.25 & $30 / 32$ & 93.75 \\
\hline Candida albicans & $2 / 16$ & 12.5 & $14 / 16$ & 87.5 & $12 / 32$ & 37.5 & $20 / 32$ & 62.5 \\
\hline Other Candida spp. & $3 / 16$ & 18.75 & $13 / 16$ & 81.25 & $3 / 32$ & 9.37 & $29 / 32$ & 90.62 \\
\hline
\end{tabular}

\section{Antibiotics sensitivity of isolated microbs}

K. pneumonia is sensitive to Minocycline, Colistin and Ritampian but it resistant to other antibiotics Ticarcillin, Piperacillin, Piperacillin/Tazobactam,
Ceftazidime, Cefepime, Aztreonam, Imipenem, Meropenem Amikacin, Gentamycin, Tobramycin, Ciprofloxacin, Pefloxacin and Trimethoprim/ sulfamethoxazole (Table 2).

Table 2. Antibiotics sensitivity of K. pneumonia determined Interpretation by MIC.

\begin{tabular}{|c|c|c|c|c|c|}
\hline Antibiotics & MIC & Interpretation & Antibiotics & MIC & Interpretation \\
\hline Ticarcillin & $>=128$ & $\mathrm{R}$ & Amikacin & $>=64$ & $\mathrm{R}$ \\
Ticarcillin/Clavulanic Acid & $>=16$ & $\mathrm{R}$ & Gentamycin & $>=16$ & $\mathrm{R}$ \\
Piperacillin & $>=128$ & $\mathrm{R}$ & Tobramycin & $>=16$ & $\mathrm{R}$ \\
Piperacillin/Tazobactam & $>=128$ & $\mathrm{R}$ & Ciprofloxacin & $>=4$ & $\mathrm{R}$ \\
Ceftazidime & $>=64$ & $\mathrm{R}$ & Pefloxacin & $>=64$ & $\mathrm{R}$ \\
Cefepime & $>=64$ & $\mathrm{R}$ & Minocycline & $<=1$ & $\mathrm{~S}$ \\
Aztreonam & $>=64$ & $\mathrm{R}$ & Colistin & $<=0.5$ & $\mathrm{~S}$ \\
Imipenem & $>=16$ & $\mathrm{R}$ & Rifampicin & $<.0 .5$ & $\mathrm{~S}$ \\
Meropenem & $>=16$ & $\mathrm{R}$ & Trimethoprim/sulfamethoxazole & $>=320$ & $\mathrm{R}$ \\
\hline
\end{tabular}


E. coli is antibiotics sensitive to Piperacillin/ Tazobactam, Meropenem, Amikacin and Nitrofurantoin. E. coli is resistant to Ampicillin, Ampicillin/Sulbactam, Cefazolin, Ceftazidime, Ceftriaxone,
Cefepime, Gentamycin, Tobramycin, Ciprofloxacin, Levofloxacin and Trimethoprim/sulfamethoxazole (Table 3).

Table 3. Antibiotics sensitivity of E.coli determined Interpretation by MIC.

\begin{tabular}{|c|c|c|c|c|c|}
\hline Antibiotics & MIC & Interpretation & Antibiotics & MIC & Interpretation \\
\hline ESBL & Pos & + & Meropenem & $<=0.25$ & $\mathrm{~S}$ \\
Ampicillin & $>=32$ & $\mathrm{R}$ & Amikacin & 8 & $\mathrm{~S}$ \\
Ampicillin/Sulbactam & $>=32$ & $\mathrm{R}$ & Gentamycin & $>=16$ & $\mathrm{R}$ \\
Piperacillin/Tazobactam & 8 & $\mathrm{~S}$ & Tobramycin & $>=16$ & $\mathrm{R}$ \\
Cefazolin & $>=64$ & $\mathrm{R}$ & Ciprofloxacin & $>=4$ & $\mathrm{R}$ \\
Cefoxitin & 16 & $\mathrm{I}$ & Levofloxacin & $>=8$ & $\mathrm{R}$ \\
Ceftazidime & 16 & $\mathrm{R}$ & Nitrofurantoin & $<=16$ & $\mathrm{~S}$ \\
Ceftriaxone & $>=64$ & $\mathrm{R}$ & Trimethoprim/sulfamethoxazole & $>=320$ & $\mathrm{R}$ \\
Cefepime & 2 & $\mathrm{R}$ & & & \\
\hline
\end{tabular}

+= Deduced drug Pos= Positive

Candida species are sensitive to Fluconazole, Voriconazole, Caspofungin, Micafungin,

Amphotericin B and Flucytosine. The minimum inhibitory concentration for antibiotic also detected as: $($ Fluconazole) $<=1$, (Voriconazole) $<=0.12$, (Caspofungin) $<=0.25$, (Micafungin) $<=0.06$, $($ Amphotericin B) $<=0.5$, (Flucytosine $)<=1$.

\section{Antibacterial activity of bacteriocin}

Antimicrobial activity of bacteriocin was tested against multidrug resistence bacteria (K. pneumonia and E. coli) and Candida spp. (C. albicans, C. tropicalis, C. famata, C. parapsilosis, C. catenulate).
Bacteriocin composition: The amino acid of the purified bacteriocin of Lactobacillus acidophilus which was pooled from ion exchange chromatography are recorded in Table (4) seventeen amino acids were detected with different amount in the purified bacteriocin. Aspartic (ASP), Glutamic (GLU), Glycine(GLY), Alanine (ALA), Proline $(P R O)$ present in the higher amount compared to Therionine (THR), Serine (SER), Valine (VAL), Isoleucine (ILE), Leucine(LEU), Tyrosine (TYR), Phenylalanine (PHE), Hisitidine ( HIS), Lysine (LYS), Argnine (ARG), Cystine (CYS), Methionine.

Table 4. Amino acid composition of Bacteriocine produced by L. acidophilus

\begin{tabular}{|c|c|c|c|}
\hline Amino acids & $\begin{array}{c}\text { Amount } \\
\mathbf{g} / \mathbf{1 0 0} \mathbf{~} \mathbf{l}\end{array}$ & Amino acids & $\begin{array}{c}\text { Amount } \\
\mathbf{g} / \mathbf{1 0 0} \mathbf{~ m l}\end{array}$ \\
\hline Aspartic (ASP) & 0.10 & Tyrosine (TYR) & 0.03 \\
Therionine ( THR) & 0.01 & Phenylalanine (PHE) & 0.04 \\
Serine (SER) & 0.02 & Hisitidine (HIS) & 0.01 \\
Glutamic (GLU) & 0.19 & Lysine (LYS) & 0.06 \\
Glycine (GLY) & 0.33 & Argnine (ARG) & 0.05 \\
Alanine (ALA) & 0.16 & Proline (PRO) & 0.19 \\
Valine (VAL) & 0.07 & Cystine (CYS) & 0.005 \\
Isoleucine (ILE) & 0.02 & Methionine & 0.01 \\
Leucine (LEU) & 0.05 & & \\
\hline
\end{tabular}



female genital tract and its effect on the ivf outcome

The agar diffusion method was used to study the effect of antimicrobial activity of Lactobacillus. acidophilus which was mixed with $\mathrm{E}$. coli, $K$. pneumonia, C. albicans, C. tropicalis, C. famata, $C$. parapsilosis, C. catenulate,

Table (5) demonstrate that the antimicrobial activity of Lactobacillus acidophilus against pathogenic isolates, the highest inhibition zone diameter was detected with E. coli $13.38 \pm 0.46$, C. albicans isolates showed inhibition zone diameter range $(6.7 \pm 0.46, \quad 7.16 \pm 0.46, \quad 14.5 \pm 0.92, \quad 11.9 \pm 0.72$, $13.33 \pm 0.66$ and $11.4 \pm 0.83)$, C. parapsilosis showed inhibition zone diameter $12.16 \pm 0.96$, C. tropicalis showed inhibition zone diameter $11.06 \pm 0.66, C$. famata showed inhibition zone diameter $3.16 \pm 0.46$ while $K$. pneumonia showed inhibition zone 9.33 \pm 0.66 . C. catenulata exhibited resistance to bacteriocin.

Table 5. The antibacterial activity of Lactobacillus growth $(1 \mathrm{~mm} / \mathrm{disc})$ based on the growth inhibition of clinical microbes isolates by disc diffusion method

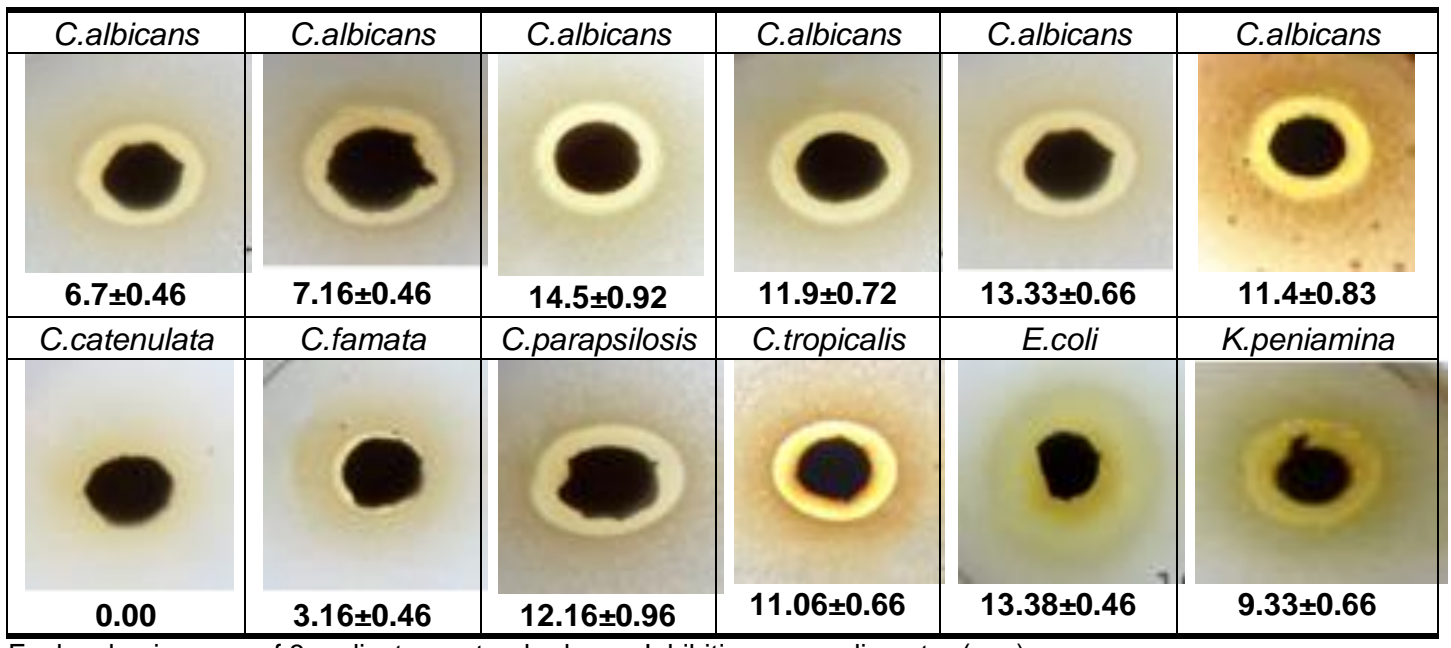

Each value is mean of 3 replicates \pm standard error Inhibition zones diameter $(\mathrm{mm})$.

The inhibition zone of clinical microbe isolates: Lactobacillus cell culture was tested against pathogenic bacteria E. coli, K. pneumonia, C. albicans, C. tropicalis, C. famata, C. parapsilosis, C. catenulate by agar well diffusion method. The inhibition zone is increased with increase bacteriocin concentration. The inhibition zone of $C$. albicans in the concentration $100 \%$ is $11.9 \pm 0.72$ but in the concentration $25 \%$ is $5.95 \pm 0.27$.The inhibition zone of $C$. tropicalis in the concentration $100 \%$ is $7.16 \pm 0.46$ but in the concentration $25 \%$ is $2.69 \pm 0.49$. The inhibition zone of $C$. famata in the concentration $100 \%$ is $3.16 \pm 0.46$ but in the concentration $25 \%$ is 0 . The inhibition zone of C. parapsilosis in the concentration $100 \%$ is $12.16 \pm 0.96$ but in the concentration $25 \%$ is $6.49 \pm 0.76$. The inhibition zone of $C$. catenulata in the concentration $100 \%$ is 0 but in the concentration $25 \%$ is 0 . The inhibition zone of $E$. coli in the concentration $100 \%$ is $13.38 \pm 0.46$ but in the concentration $25 \%$ is $4.76 \pm 0.67$. The inhibition zone of $K$. peniamina in the concentration $100 \%$ is $9.33 \pm 0.66$ but in the concentration $25 \%$ is $4.45 \pm 0.58$. (Table 6).

Antimicrobial activity of bacteriocin produced by L. acidophilus in PPE was studied against sensitive bacterial and Candida by critical dilution assays. Results are given in Table 7 by titration of PPE, about (4.00 to 7.00); (5.00 to 3.15); (8.00 to $5.45)$ and (6.00 to 347) CFU $\mathrm{mL}^{-1}$ were obtained with $K$ penumina; Candida.alb -1; Candida.alb -2 and $E$. coli, respectively. 
Table 6. Antimicrobial activity of bacteriocin against clinical microbes determined by the agar well diffusion and critical dilution assays

\begin{tabular}{|c|c|c|c|c|}
\hline \multirow{2}{*}{ Clinical microbes } & \multicolumn{4}{|c|}{ Bacterocin concentration } \\
\cline { 2 - 5 } & $\mathbf{2 5 \%}$ & $\mathbf{5 0} \%$ & $\mathbf{7 5 \%}$ & $\mathbf{1 0 0}$ \\
\hline C.albicans & $5.95 \pm 0.27$ & $8.74 \pm 0.19$ & $10.25 \pm 0.98$ & $11.9 \pm 0.72$ \\
C.tropicalis & $2.69 \pm 0.49$ & $4.65 \pm 0.72$ & $5.65 \pm 0.76$ & $7.16 \pm 0.46$ \\
C.famata & 0.00 & 0.00 & 0.00 & $3.16 \pm 0.46$ \\
C.parapsilosis & $6.49 \pm 0.76$ & $8.12 \pm 0.59$ & $9.58 \pm 0.82$ & $12.16 \pm 0.96$ \\
C.catenulata & 0.00 & 0.00 & 0.00 & 0.00 \\
E.coli & $4.76 \pm 0.67$ & $8.75 \pm 0.91$ & $12.15 \pm 0.69$ & $13.38 \pm 0.46$ \\
K.peniamina & $4.45 \pm 0.58$ & $6.25 \pm 0.76$ & $8.13 \pm 0.65$ & $9.33 \pm 0.66$ \\
\hline
\end{tabular}

${ }^{*}$ Inhibition zone diameter $=(\mathrm{mm})$ calculated from three replicates for each concentration

Table 7. Growth of isolated clinical microbes in nutrient broth medium with or without partially purified bacterocin

\begin{tabular}{|c|c|c|c|c|c|c|c|c|}
\hline \multirow{2}{*}{$\begin{array}{c}\text { Time } \\
\text { (min.) }\end{array}$} & \multicolumn{8}{|c|}{ Log $\left(\right.$ CFUml $\left.^{-1}\right)$} \\
\cline { 2 - 8 } & K pneumonia. & \multicolumn{2}{|c|}{ Candida.alb -1 } & \multicolumn{2}{c|}{ Candida.alb -2 } & \multicolumn{2}{|c|}{ E.coli } \\
\cline { 2 - 8 } & Cont. & Treat. & Cont. & Treat. & Cont. & Treat. & Cont. & Treat. \\
\hline 0 & 7.00 & 7.00 & 5.00 & 5.00 & 8.00 & 8.00 & 6.00 & 6.00 \\
5 & 7.10 & 6.90 & 5.17 & 4.95 & 8.15 & 7.85 & 6.15 & 5.85 \\
10 & 7.36 & 6.73 & 5.63 & 4.75 & 8.45 & 7.72 & 6.45 & 5.62 \\
15 & 7.58 & 6.58 & 5.85 & 4.55 & 8.67 & 7.61 & 6.67 & 5.51 \\
20 & 7.63 & 6.19 & 6.15 & 4.39 & 8.82 & 7.50 & 6.82 & 5.30 \\
25 & 7.79 & 5.85 & 6.25 & 4.25 & 9.05 & 7.22 & 7.05 & 5.12 \\
30 & 7.92 & 5.26 & 6.75 & 4.10 & 9.18 & 6.75 & 7.18 & 4.95 \\
35 & 8.14 & 5.00 & 7.12 & 3.90 & 9.23 & 6.52 & 7.32 & 4.72 \\
40 & 835 & 4.85 & 7.23 & 3.85 & 9.59 & 6.39 & 7.59 & 4.49 \\
45 & 8.58 & 4.65 & 7.35 & 3.75 & 9.75 & 6.25 & 7.75 & 4.25 \\
50 & 8.62 & 4.37 & 7.50 & 3.67 & 9.95 & 6.10 & 8.05 & 4.00 \\
55 & 8.75 & 4.23 & 7.75 & 3.43 & 10.15 & 5.65 & 8.25 & 3.75 \\
60 & 9.00 & 4.00 & 8.00 & 3.15 & 10.38 & 5.45 & 8.58 & 3.47 \\
\hline
\end{tabular}

Cont. = Control without treatment

Treat. $=$ Treatment

The broth media of pathogenic tested microorganisms without and with bacteriocinl (control and treated groups respectively) to test antimicrobial activity against $K$ pneumonia, Candida.alb -1 , Candida.alb -2 and E.coli as pathogenic clinical isolates, using well -defined cell concentration standardized, the concentration of bacterial cells was determined by standard of CFU counting (Schellenberg, et al 2006) (Table 7). The data show that Lactobacillus acidophilus produced the antibacterial compounds reducing the number of pathogenic cells 4 log 10CFU of $K$ pneumonia , 3.15, $5.45 \log 10 \mathrm{CFU}$ of Candida.alb -1, Candida.alb -2 respectively and3.47 log 10CFU of E.coli.

\section{DISCUSSION}

Pathological bacteria and candida isolated from vagina, endocervical canal and tip of catheter were identified according to Bergey's Manual of Determinative Bacteriology (Holt, et al 1994) and con- 

female genital tract and its effect on the ivf outcome

firmed by VITEK 2 system as Klebsilla pneumonia, E.coli, C. albicans, C. tropicalis, C. famata, C. parapsilosis and C. catenulate (Selman, et al 2007).

The vitek analyser was found to be valuable for the speed and accuracy, there are separate cards for Gram positive, Gram negative and yeasts yeast like organisms, also contain antimicrobial susceptibility test that can determine the minimum inhibitory concentration (MIC) against organism. (Shetty, et al 1998 and Funke, et al 1998).

The pregnancy rate is lower in presence of pathogenic bacteria (K. pneumonia. E. coli) and Candida spp., comparable with those with negative microbial growth with agreement with (Eskandar, et al 2007).

The bacterial contamination has negatively effect on fertility, fertilization and implantation rate (Selman, et al 2007). During embryo transfer techniques, embryos are loaded into a transfer catheter that passes through vagina and cervix into the uterus that may lead to possible microbial contamination of the uterine cavity that may alter the susceptibility of the endometerium and embryo implantation (Aboul fotouh, et al 2008). There are many factors that affect on implantation rates such as patient's age, endometrial receptivity and embryo quality (Egbase, et al 1996). The presence of pathogenic bacteria such as E.coli and streptococcus viridians decreased live birh rate ( Eckert, et al 2003). The enterobacteriaceae represent the most pathogenic bacteria affect the genital tract, Escherichia coli considered the most isolated species followed by klebsilla (Selman, et al 2007). Bacterial vaginosis represents a common imbalance of the vaginal bacterial flora that have pathogenic effects including increased rate of late miscarriage, premature rupture of the membrane, endometritis, to preterm labour and delivery (Liversedge, 1999). Disequilibrium in microbiota can favor the growth of opportunist microorganisms and the development of pathologies, such as candidosis, an infection caused by yeasts of the Candida genus. Vulvovaginal candidiasis (VVC) is overgrowth of candida spp. due to the disruption of the vaginal microbiota may be due to pregnancy, antibiotic therapy, use of contraceptives and spermicide, frequent sexual intercourse, diabetes and immunosuppression (Rathod, et al 2014 and sobel, 2007). Candida albicans is the commensal yeast of the oral, gastrointestinal and vagina mucosa in a healthy woman, but the overgrowth of these organism may change from commensal to pathogenic organism (Chakoosari, 2013). Candida albicans is the major causal of yeast Vaginitis but there are another species Candida glabrata, Candida krusei and Candida tropicalis infect the host. The development of VVC has been associated with the lack of $\mathrm{H}_{2} \mathrm{O}_{2}$-producing lactobacillus species (Vitali, et al 2007). The normal vaginal flora of the human play an important role in preventing colonization of the pathogen including those responsible for bacterial vaginosis, yeast infections, sexually transmitted disease and urinary tract infection (Zhou, et al 2004 and Burton, et al 2003). The microflora of a health human vagina include 50 species of organisms which differ in composition according to several factors such as age, menarche, time in the menstrual cycle, pregnancy and infection (Reid, 2001 and Zhou et al 2004). Lactobacillus is the dominant organism of the vaginal flora that have an important role in the inhibition of pathogen (Cannon, 2005).

In this study, Lactobacillus acidophilus and its metabolites bacteriocin were tested against pathogenic isolates. The results detected that $L$. acidophilus and bacteriocin have inhibitory effect against pathogens.

Lactobacilli especially $L$. acidophilus, L. cripatus, $L$. jensenii and $L$. iners are considered the most dominant microorganisms in the vagina of healthy premenopausal women (Cannon, 2005). Lactobacillus can inhibit the growth of pathogens by two mechanisms : (a) by production of antimicrobial factors that have adverse effect of pathogens such as lactic acid, hydrogen peroxide, bacteriocin and bacteriocin like substance such as nisin , lactobrevin, acidophilin, acidolin, lactobacillin, lactocidin and lactolin (Chakoosari, 2013 and Pendharkar, et al 2015). (b) by adherence and competition. The mechanism of defence of lactobacillus against candida colonization is the ability of lactobacilli to adhere and compete for receptors sites on vagin al epithelial cells (Simonetti, et al 2007). Biasoli and Magaró, (2003). observed that the introduction of $L$. casei and $L$. acidophilus in vitro inhibit the adhesion of candida albicans. Lactobacilli are able to inhibit histone deacetylases (HDACs) that affect morphogenesis and virulence factor that lead to reduce the adhesion of candida $\mathrm{sp}$. to vaginal mucosa. Butyrate and lactate are known as HDACs inhibitors. HDACs inbibitors improve sensitivity of candida albicans to azole drugs (Nguyen, et al 2011 and latham, et al 2012).

\section{CONCLUSION}

The presence of pathogenic bacteria (Klebsilla pneumonia and E.coli) and C. albicans, C. tropical- 
is, C. famata, C. parapsilosis and C. catenulate) have adverse effect on implantation rate and pregnancy outcome. Candida albicans is the commensal yeast of the oral, gastrointestinal and vagina mucosa in a healthy woman, but the overgrowth of these organism may change from commensal to pathogenic organism. Lactobacillus has antagonist activity against pathogen. This study detected that the use of Lactobacillus cells or its metabolites bacteriocin can inhibit the pathogens. This study aim to application Lactobacillus or bacteriocin antiseptics; disinfected to maintain a health vagina and prevent the infection of the reproductive tract.

\section{REFERENCES}

Aboul Fotouh I. and Gaber Al-Inany M. 2008. The levels of bacterial contamination of the embryo transfer catheter relate negatively to the outcome of embryo transfer. Middle East Fertility Society J., 13(1), 39-43.

Biasoli, M.S. and Magaró, H.M. 2003. In vitro of carbohydrates and enteric bacteria on adherence of Candida albicans. Rev. Iberoam. Micol. 20(4), 160-163.

Burton, J.P., Cadieux, P.A. and Reid, G. 2003. Improved understanding of the bacterial vaginal microbiota of women before and after probiotic instillation. Appl Environ Microbiol., 69, 97101.

Cannon, J.P., Lee, T.A., Bolanos, J.T. and Danziger, L.H. 2005. Pathogenic relevance of Lactobacillus: a retrospective review of over 200 cases. Eur J. Clin Microbiol Infect Dis. 24, 31-40.

Chakoosari, M.M.D. 2013. Probiotics for prevention of Candida Infections. J. of Biology and Today's World, 2(9), 412-416.

Cheesbroughg, M. 2000. District laboratory practice in tropical countries. part 2 University press, Cambridge, UK. 434 p.

Csomos, E. and Simon-Sarkadi, L. 2002 . Characterisation of Tokaj wines based on free amino acids and biogenic amines using ionexchange chromatography. Chromatographia, 56, S185-S188.

Eckert, L.O., Moore, D.E., Patton, D.L., Agnew K.J. and Eschenbach, D.A. 2003. Relationship of vaginal bacteria and inflammation with conception and early pregnancy loss following in-vitro fertilization. Infectious Diseases in Obstetrics and Gynecology 11, 11-17.
Egbase, P.E., Al-Sharhan, M., Al-Othman, S., AlMutawa, M., Udo, E.E. and Grudzinskas, J.G.. 1996. Incidence of microbial growth from the tip of embryo transfer catheter after embryo transfer in relation to clinical pregnancy rate following in -vitro fertilization and embryo transfer. Hum Reprod; 11, 1687-1689.

Egbase, P.E., Udo, E.E., Al-Sharhan, M. and Grudzinskas, J.G. 1999. Prophylactic antibiotics and endocervical microbial inoculation of the endometrium at embryo transfer (letter). Lancet, 354, 651-652.

Enan, G., Shaaban, K., Askora, A. and Maher, M. 2013. Evaluation of the use of novel coliphages to control Escherichia coli W1 and Escherichia coli W2. Res. J. Applied Sci., 8, 486-493.

Eskandar, M. 2007. Removal of cervical mucus prior to embryo transfer improves pregnancy rates in women undergoing assisted reproduction. Reproductive Bio. Medicine Online. 14(3), 308-313.

Funke, G., Monnet, D., Bernardis, C., Graevenitz A. and Freney, J. 1998. Evaluation of the VITEK2 system for rapid identification of medically relevant Gram -Negative rods. J. of Clinical Microbiology 36(7), 1948-1952.

Hnisz, D., Majer, O., Frohner, I.E., Komnenovic, V. and Kuchler, K. 2010. The Set3/Hos2 histone deacetylase complex attenuates cAMP/PKA signaling to regulate morphogenesis and virulence of Candida albicans. PLoS Pathog. 6:e1000889

Holt, J.G., Krieg, N.R., Sneath, P.H.A., Stanley, J.T. and Williams, S.T. 1994. Bergey's manual of determinative bacteriology ( $9^{\text {th }}$ ed., Williams and Wilkins, Baltimore), $787 \mathbf{p}$.

Latham, T., Mackay, L., Sproul, D., Karim, M., Culley, J., Harrison, D.J., Hayward L., Langridge-Smith, P., Gilbert, N. and Ramsahoye, B.H. 2012. Lactate, a product of glycolytic metabolism, inhibits histone deacetylase activity and promotes changes in gene expression. Nucleic Acids Res. 40, 4794-4803.

Liversedge, N.H., Turner, A., Horner, P.J., Keay, S.D., Jenkins, J.M. and Hull, M.G.R. 1999. The influence of bacterial vaginosis on in-vitro fertilization and embryo implantation during assisted reproduction treatment. Human Reproduction 14, 2411-2415.

Moore, D.E., Soules, M.R., Klein, N.A., Fujimoto, V.Y., Agnew, K.J. and Eschenbach, D.A. 2000. Bacteria in the transfer catheter tip influ- 
ence the live- birth rate after in vitro fertilization. Fertil Steril; 74, 1118-1124.

Nguyen, L.N., Lopes, L.C., Cordero, R.J. and Nosanchuk, J.D. 2011. Sodium butyrate inhibits pathogenic yeast growth and enhances the functions of macrophages. J. Antimicrob Chemother. 66, 2573-2580.

Ouda, S., Debevere, J. and Enan, G. 2014. Purification and biochemical characterization of plantaricin produced by Lactobacillus plantarum UG1 isolated from dry sausage. Life Sci. J. 114, 271-279.

Pendharkar, S., Brandsborg, E., Hammarström, L., Marcotte, H. and Larsson, P. 2015. Vaginal colonisation by probiotic lactobacilli and clinical outcome in women conventionally treated for bacterial vaginosis and yeast infection BMC Infectious Diseases (2015) pp. 215255.

Rathod, S.D. and Buffler, P.A. 2014. Highly-cited estimates of the cumulative incidence and recurrence of vulvovaginal candidiasis are inadequately documented. BMC Women's Health. pp. 14-43.

Reid, G., Beuerman, D., Heinemann, C. and Bruce, A.W. 2001. Probiotic Lactobacillus dose required to restore and maintain a normal vaginal flora. FEMS Immunol Med Microbiol. 32, 37-41.

Schellenberg, W., Smoragiewicz, B. and Karska-Wysocki . 2006. A rapid method combining immunofluorescence and flow cytometry for improved understanding of competitive interactions between lactic acid bacteria (LAB) and methicillin -resistant $S$. aureus (MRSR) in mixed culture. J. of Microbiology Methods, 65, 1-9.

Selman, H., Mariani, M., Barnocchi, N., Mencassi, A., Bistoni, F., Arena, S., Pizzasegale, S., Brusco, G.F. and Angelini, A. 2007. Examination of bacterial contamination at the time of embryo transfer and its impact on the ivf / pregnancy outcome. J. Assist Reprod Genet., 24, 395-399.

Shetty, N., Hill, G. and Ridgway, G.L. 1998. The vitek analyser for routine bacterial identification and susceptibility testing: protocols - problems and pitfalls. J. Clin Pathol., 51, 316-323.

Simonetti, G., Passariello, C., Rotili, D., Mai, A., Garaci, E. and Palamara, A.T. 2007. Histone deacetylase inhibitors may reduce pathogenicity and virulence in Candida albicans. FEMS Yeast Res., 7, 1371-1380.

Sobel, J.D. 2007. Vulvovaginal candidosis. Lancet., 369, 1961-1971.

Vitali, B., Pugliese, C., Biagi, E., Candela, M., Turroni, S., Bellen, G., Donders, G.G. and Brigidi, P. 2007. Dynamics of vaginal bacterial communities in women developing bacterial vaginosis, candidiasis, or no infection, analyzed by PCR-denaturing gradient gel electrophoresis and real-time PCR. Appl. Environ Microbiol., 73, 5731-5741.

Zhou X, Bent SJ, Schneider MG, Davis CC, Islam MR and Forney LJ 2004. Characterization of vaginal microbial communities in adult healthy women using cultivation independent methods. Microbiology. Aug., 150(Pt8), 256573. 